Journal of

Accident and

Emergency

Medicine 1994

11, 246-249

\title{
Audit of telephone advice in a paediatric accident and emergency department
}

\author{
E. MOLYNEUX, N.JONES, G.ALDOM \& B.MOLYNEUX \\ Department of Accident and Emergency Medicine Royal Liverpool Children's Hospital, Liverpool
}

\section{SUMMARY}

This paper audits the telephone requests for advice to a paediatric accident and emergency (A\&E) Department over a 4-week period. All calls were answered by senior nurses. Most calls were received in the early evenings when the A\&E department was busy. Parents were the most frequent callers and the majority of calls were for children under 5 years of age. The problems presented were wide ranging but advice over the telephone meant that many unnecessary visits to hospital were prevented. The public use the A\&E department as a primary source for health advice and very few of the calls resulted in admissions. This telephone advice service is effective and helpful to the public but time consuming for A\&E nursing staff at peak workload periods in their own department.

Key words: accident and emergency, children, telephone advice

\section{INTRODUCTION}

Members of the public use the telephone to seek advice from A\&E departments and each A\&E has its own procedure for handling such calls. In the A\&E department of the Royal Liverpool Children's Hospital, where 55000 new patients are seen each year, an experienced nurse gives advice in response to telephoned enquiries. She records the caller's name and telephone number, the relationship of the caller to the child concerned, the child's name and age, the problem for which advice is requested and the advice given. The time of the call is also noted. When it became clear that calls to this department were frequent and time-consuming this audit was proposed. The objective was to answer several questions: Who calls, when and with what problems? Are the problems such that advice can be given over the telephone, and do callers follow the advice given? How much time does this service take up and is the service effective in helping the public? Does the service encourage necessary visits to the A\&E department, general practitioners or health centres, and does it prevent unnecessary ones?

\section{METHODS}

During the 4-week period, 29 June to 26 July 1992 a questionnaire was completed for each telephone call from a member of the public who was requesting medical advice. The auditor received the call and recorded the following details:

(1) time call received,

(2) callers relationship to child,

(3) telephone number,

(4) name of child,

(5) age of child,

(6) address of child,

(7) who advised caller to contact A\&E department,

(8) did the caller try any other sources for advice - if yes, where and what was the outcome and

(9) has the child been seen already with this problem - if yes, by whom.

The auditor then located an available experienced nurse in the department and passed on the call and the questionnaire to her or him. The nurse dealt with the call and recorded the following information:

(1) the problem for which advice was requested,

(2) the advice given,

(3) whether she thought this a suitable problem for telephoned advice,

(4) whether she thought the advice would either encourage or prevent a visit to the A\&E department or the general practitioner (GP) and

(5) the length of time of the call.

Each telephone call was followed up 2 days later to check whether or not the child subsequently attended the A\&E department. These data were entered on Database IV for subsequent analysis. 


\section{E. Molyneux et al. RESULTS}

\section{Number and time of calls}

A total of 764 telephone enquiries were received over the 4-week period with an average of 27 calls a day. There were more calls on Thursdays, Saturdays and Sundays than on other days of the week (Fig. 1). This may be because many local GPs have a half day on Thursday and hold no weekend surgeries. Most telephone calls were received in the early evening between 17.00 and $22.00 \mathrm{~h}$ (Fig. 2).

The average time each call took was $5.6 \mathrm{~min}$. However, calls varied considerably in length (range $1-34 \mathrm{~min}$ ). Most calls ( 710 out of $764 ; 93 \%$ ) could be dealt with in less than 10 min but 15 calls took over 15 min (Fig. 3).

\section{Who made the calls and for whom}

Most callers were either mother $(74 \%)$ or father $(15 \%)$ : a grandmother or an aunt initiated a further 51 calls $(7 \%)$. Other calls were from neighbours, teachers, guardians or friends. In 16 cases the caller's relationship was not identified. Calls tended to be made on behalf of young children and infants. A total of 503 calls $(66 \%)$ were made for children under 5 years of age of whom $146(19 \%)$ were for babies of less than 1 year. A further 146 calls $(19 \%)$ were for children between the age of 5 and 10 years, (Fig. 4).
The problem for which advice was requested

The calls were for a wide variety of perceived emergencies. Accidental ingestion of a substance was the most common single problem (110 calls, $14 \%$ of total). Head injuries accounted for 89 calls $(12 \%)$. Diarrhoea and vomiting and fever were other commonly expressed concerns for which advice was requested. Table 1 shows the order of frequency of complaints and also how many callers were advised to attend the A\&E department or chose to attend following the advice they had been given.

Who advised caller to contact the A\&E department

The bulk of enquiries were from people using the department as their primary source of information and advice. A total of $646(84 \%)$ had made the decision to call the A\&E department themselves. Thirty-seven ( $5 \%$ ) had been advised to contact the A\&E department by their own GP and $16(2 \%)$ by another hospital. Seventeen people (2\%) had received advice to contact the A\&E department from a variety of other people such as teachers, family members or neighbours.

A total of $525(69 \%)$ callers had not taken their child for examination for this problem to any health carer and $128(17 \%)$ had already seen their GP. A few had been to the baby clinic (32) or were seen by the health visitor $(<1 \%)$.
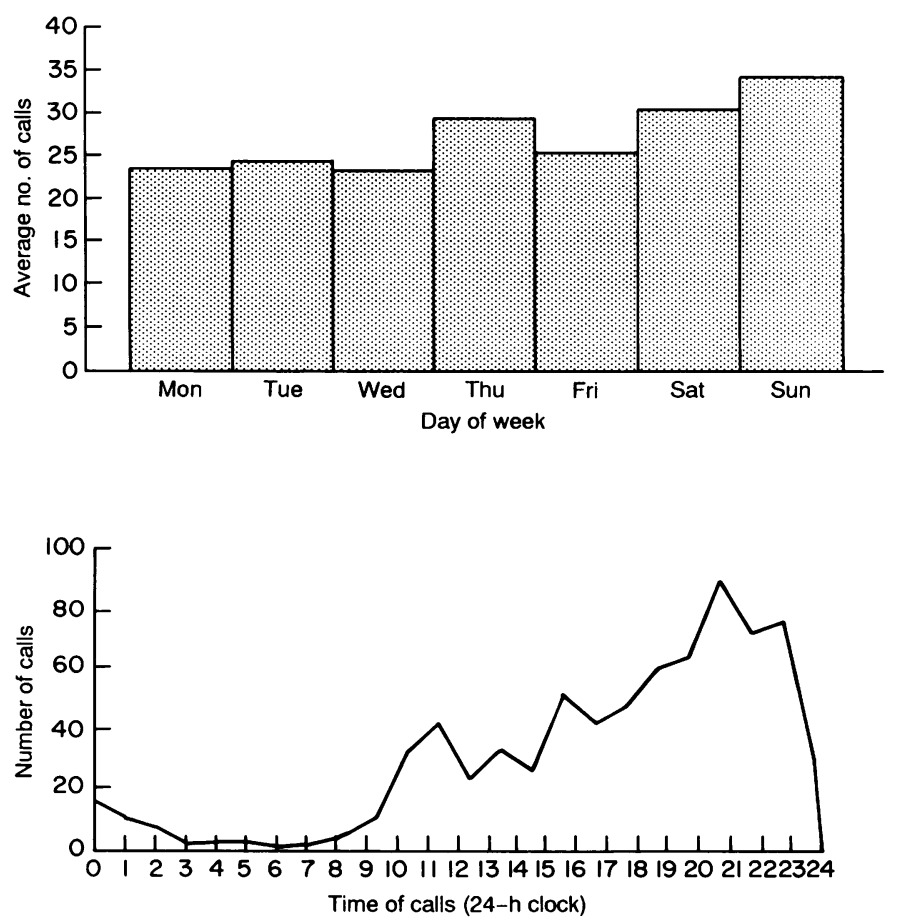

Fig. 1. Number of telephone advice calls each day.

Fig. 2. Hourly distribution of calls. 
Telephone advice in a paediatric $A \& E$ department

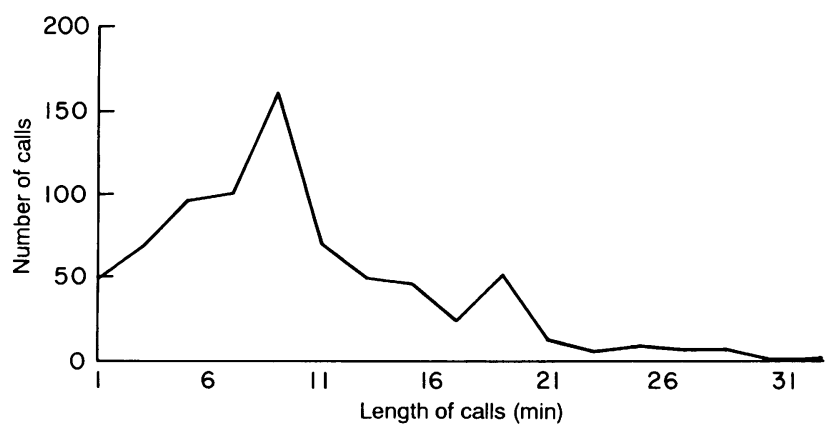

Fig. 3. Duration of calls.

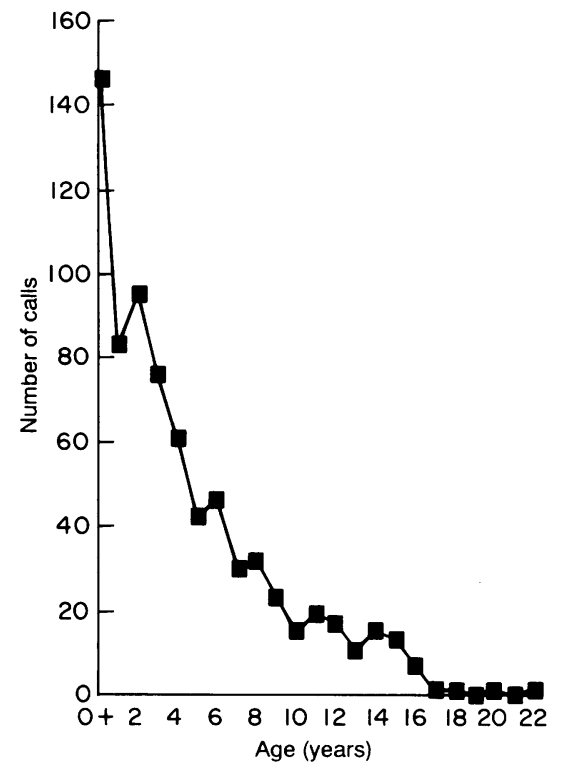

Fig. 4. Age of child for whom advice was sought.

\section{What advice was given}

A total of 259 people (34\%) were advised to come to the A\&E department. A further $214(28 \%)$ were given general advice and $92(12 \%)$ were felt to need reassurance only. A further $145(19 \%)$ were advised to attend their own GP and $38(5 \%)$ were advised that another A\&E department, health visitor or well baby clinic would be a suitable place to attend with their problem. Of all the calls, $630(82 \%)$ were, in the opinion of the nurse taking the call, suitable for telephone advice and in $66 \%$ it was not considered necessary to advise attendance at the A\&E department. The majority of queries concerning ingestions or head injuries could be dealt with in this way, as could queries concerning tetanus immunizations. Calls about medical problems such as fever were more likely to receive the advice that
Table 1. Problems for which telephone advice was sought

\begin{tabular}{lrc}
\hline Problem & Total Calls & Attended \\
\hline Ingestion & 110 & 30 \\
Head Injury & 89 & 28 \\
Diarrhoea/vomiting & 75 & 19 \\
Fever & 46 & 35 \\
Hand/foot injury & 31 & 20 \\
General enquiries & 31 & 16 \\
Tetanus enquiry & 30 & 2 \\
Rash/measles etc. & 30 & 4 \\
Mouth injury/infection & 28 & 3 \\
Limb injury & 26 & 14 \\
Constipation/abnormal stools & 22 & 6 \\
Tummy pains & 17 & 6 \\
Stings & 17 & 2 \\
Ear injury/infection & 17 & 7 \\
Wheezy & 14 & 7 \\
Bleeding/discharge/nosebleeds & 14 & 2 \\
Eye injury/infection & 13 & 4 \\
Urinary problems & 12 & 4 \\
Burn/blister/bruising & 11 & 6 \\
Sore throat/tonsillitis & 8 & 4 \\
Not feeding & 7 & 4 \\
Cough & 5 & 0 \\
Coryza & 5 & 2 \\
Other & 105 & 20 \\
\hline
\end{tabular}

\section{Outcome}

A total of 245 children (32\%) subsequently attended the A\&E department. Of those advised to attend, $67 \%$ actually did so while $41 \%$ of those advised to go to their GP or other source still chose to come to the A\&E department. Nineteen children (2.4\%) required admission. In all cases requiring admission the parents had been advised to come to the A\&E department. Of the callers who were reassured that they did not need to come to the A\&E department but nevertheless attended, 20 in number, none required admission. 


\section{E. Molyneux et al. DISCUSSION}

During the 4-week period 764 calls were logged, averaging 191 calls a week or 27 a day. In total over the 4-week period covered by the audit $71.4 \mathrm{~h}$ were spent answering advice calls. A large proportion of these calls came in the early evening when the department is very busy. At this time of the day a senior nurse could be answering calls for $15 \mathrm{~min}$ out of every hour. It was anticipated that the totals would be higher outside GP surgery hours, i.e. evenings and weekends, and this proved to be true.

The most frequently recurring problems for which advice is sought appear to be the ones most easily dealt with by telephone and this advice prevents a large number of unnecessary visits to the department or to GPs. Thus, of all enquiries concerning accidental ingestion only $27 \%$ needed to attend the A\&E department. Thirty-one per cent of calls covering head injuries and $25 \%$ covering diarrhoea and vomiting led to hospital attendances.

Evans et al. ${ }^{1}$ made simulated enquiries to 18 major and 16 minor A\&E departments in Wales. They felt that in 72 out of 97 queries (74\%) appropriate advice was given. In their study $62 \%$ of calls were dealt with by nurses. None of the staff had received formal training.

Isaacman et al. ${ }^{2}$ in Pittsburgh undertook a similar study and found that in 61 emergency departments 42 calls were answered by a nurse and 10 by a physician (one was not prepared to give her background). A total of $72 \%$ of people were given advice to see a physician when a clear history of possible meningitis was given. They concluded that telephone advice could be inadequate.

In this study, in the nurse's opinion, most calls were suitable for telephoned advice. Only $17.5 \%$ were thought unsuitable; $37 \%$ were considered unlikely to prevent a visit despite reassurance and advice. In fact $68 \%$ of telephone callers did not attend the A\&E department. Perhaps the nurses underrated their ability to reassure the callers. There was no pattern to the problems which the nurses thought unsuitable for telephoned advice and no particular problem for which they thought a visit would be prevented. Guidelines for good practice in staff answering telephone enquiries have been drawn up by the BAEM Clinical Services Committee (January 1992). These guidelines advise the careful logging of all calls and recording the advice given. The staff answering such calls shall be trained nurses with appropriate A\&E experience and training in answering these queries. Litigation could arise either against an individual or a department following such advice calls so it is important to follow the guidelines and keep careful records of all calls.

The telephone advice system in the A\&E department appears to be successful in preventing a large number of unnecessary visits to either the hospital or to GPs. It provides the carers of children with reassurance and information. However, the times at which the calls are made is a busy time in the A\&E department and telephone calls interrupt and occupy a senior nurse for considerable periods of time. These calls take not only the nurses time but also that of the receptionist who answers the call and has to locate an appropriate nurse to give advice in the department. These findings need consideration when assessing staff requirements within the A\&E department.

\section{ACKNOWLEDGEMENTS}

We would like to thank all nursing staff and reception staff for their help and cooperation in completing this study.

\section{REFERENCES}

1. Evans R., McCabe M. \& Rainer T. (1992) Telephone advice in A\&ED. A survey of current practice in Wales (BAEM Abstracts). Archives of Emergency Medicine 9, 95.

2. Isaacman D.J., Verdile V.P., Kohen L.A. (1992) Pediatric telephone advice in the emergency departments: results of a mock scenario. Pediatrics 89, 35-39. 